\title{
EDITORIAL: PESQUISA E ENSINO.
} EDITORIAL: RESEARCH AND TEACHING.

\author{
João Carlos Krause ${ }^{1}$
}

Em 2021 a revista ENCITEC completou 10 anos de atividades, sempre contribuindo significativamente para a divulgação de resultados de pesquisas em Ensino. Esta aptidão da ENCITEC vai ao encontro do que a área de Ensino da CAPES traz em seu documento de área, no qual salienta que a área "é marcada principalmente por ser uma área de pesquisa translacional, buscando construir pontes entre conhecimentos acadêmicos gerados em educação e ensino, para sua aplicação em produtos e processos educativos na sociedade". Assim, a ENCITEC tem marcado sua trajetória pela publicação de pesquisas nas diversas áreas do Ensino, contribuindo, substancialmente para a disseminação das pesquisas envolvendo processos educativos, buscando manter viva esta ponte entre pesquisa e ensino.

Neste novo número, fechando este ano entre comemorações, incertezas, preocupações, perdas e o descaso com a ciência, trazemos 19 artigos sobre pesquisas relacionadas a várias áreas e um relato de experiência, e espero que estes possam de alguma forma contribuir para a melhoria efetiva do ensino em nosso pais.

O artigo de abertura desta edição, traz uma investigação sobre a construção dos sentidos produzidos pelos estudantes de ensino médio profissionalizante EJA que uma professora de Química fez de uma obra audiovisual. $\mathrm{O}$ artigo trata sobre o reendereçamento, que diz respeito às adaptações e mediações feitas por professores em obras audiovisuais para que estes cumpram uma função educativa. Os resultados apontam para o papel ativo dos alunos espectadores na negociação de sentido a partir dos materiais levados pela professora.

A importância da alfabetização científica para a formação cidadã, é tema do segundo artigo desta edição. A pesquisa abordou o livro didático como um dos materiais de cunho cientifico de principal acesso para a EJA, sendo analisado o livro Viver e Aprender: Ciência, Transformação e Cotidiano, investigando como a alfabetização científica é abordada na disciplina Química. Os autores perceberam o livro didático possui uma abordagem superficial dos conteúdos químicos, com uma perspectiva de formação voltada para o trabalho, conferindo uma abordagem muito prática à ciência. Os resultados apontam que o livro analisado apresenta falhas significativas no sentido da promoção da alfabetização científica e tecnológica aos estudantes.

Na sequência, o terceiro artigo, apresenta os resultados de uma pesquisa de mestrado tratando da produção de um vídeo educacional voltado para o ensino do conteúdo Estações do Ano, na disciplina de Ciências, anos finais do Ensino Fundamental, conjugando materiais didáticos em Astronomia e a utilização pedagógica das Tecnologias de Informação e Comunicação (NTIC). O vídeo foi pensado a partir do Modelo TPACK - Technological Pedagogical Content Knowledge e analisado por cinco professores de Ciências mediante um roteiro de

https://orcid.org/0000-0001-8674-9634. Doutor em Ciências - Física Experimental (IF-UFRGS). Editor ENCITEC e coordenador PPGEnCT (URI), Santo Ângelo, RS, Brasil. Avenida Universidade das Missões, 464. Bairro Universitário, CEP 98.802-470, Santo Ângelo, RS, Brasil. E-mail: krause@san.uri.br. 
questões. A análise das respostas, mostrou que embora sejam necessárias adequações, o vídeo apresenta pertinência pedagógica.

No quarto artigo desta edição, é apresentada uma pesquisa realizada com o objetivo de identificar trabalhos acadêmicos que abordem o ensino de genética na Educação Básica. Foram analisadas dissertações e teses da Biblioteca Digital de Teses e Dissertações Brasileiras, nos anos de 1999 a 2019, utilizando o descritor "Ensino de Genética". Os resultados indicam que prevalecem estudos acerca dos conceitos de Genética trabalhados na Educação Básica, sendo o DNA apontado como uma das principais dificuldades de aprendizagem dos alunos. Os autores concluem que a expressiva publicação de temas relacionados ao ensino de Genética pode ser um bom indicativo de como as áreas de pesquisa em Educação e em Ensino tem priorizado essa temática, indicando uma saudável preocupação com este tema.

O próximo artigo analisou as relações dos estudantes do 4음 ano do Ensino Fundamental de uma escola pública municipal de Aracaju - SE, com o aprender durante o ensino por investigação. $O$ estudo de cunho qualitativo analisou se as atividades investigativas contribuem para que o estudante se torne responsáveis na construção do próprio aprendizado. Foram realizadas entrevistas semiestruturadas onde os autores constataram que $61.9 \%$ dos estudantes desenvolveram três processos epistêmicos propostos por Charlot: i) objetivaçãodenominação; ii) imbricação do eu e iii) distanciação-regulação.

No sexto artigo, são apresentadas análises e reflexões sobre uma formação continuada vivenciada por professores dos $4^{\circ}$ e $5^{\circ}$ anos de escolas públicas municipais, com intuito de investigar as concepções e práticas dos docentes acerca das temáticas da Alfabetização Científica (AC) com enfoque da Ciência, da Tecnologia e da Sociedade (CTS). Os autores verificaram a compreensão da temática em estudo pelos professores, a partir dos relatos das sistematizações e na construção de um mapa conceitual.

A popularização do tema clonagem utilizando recursos multimídias como ferramenta pedagógica, foi o tema do sétimo artigo. $O$ artigo tratou da produção de um vídeo sobre o tema. A análise utilizada foi qualitativa por meio de questionários aplicados a graduandos do Curso de Licenciatura em Ciências Naturais da UNIFESSPA e aos estudantes do nono ano do Ensino Fundamental, de uma Escola Pública do Município de Marabá/PA. Os resultados apontaram que o uso do vídeo contribuiu para o entendimento do processo de clonagem, de forma lúdica e dinâmica e a adoção de vídeos como ferramenta didático-pedagógica motiva os estudantes.

O próximo artigo apresenta um jogo digital do tipo estratégia e simulação Simsustentabilidade, focado no ensino de questões ambientais e sustentabilidade. $O$ objetivo do jogo foi criar um espaço para ciência cidadã e formação de alunos que saibam atuar transformando a sociedade através de uma consciência ecológica. $O$ jogo foi avaliado utilizando técnicas quantitativas e qualitativas envolvendo entrevistas semiestruturadas e um estudo etnográfico. Os resultados mostraram que o jogo pode auxiliar os alunos no reforço dos conceitos e na consciência a respeito da importância da sustentabilidade.

O nono artigo, traz um estudo que analisou as perspectivas de sujeitos sobre o ensino lúdico na saúde. A metodologia utilizou uma abordagem qualitativa, com aplicação de um questionário com perguntas abertas a oito sujeitos de áreas diversas. Os depoimentos ressaltaram a relevância da abordagem do lúdico no ensino para a área da saúde, promovendo 
estímulos nas interações dos envolvidos e proporcionando atividades criativas, prazerosas e afetivas.

Na sequência, o próximo artigo discute as concepções de professores formadores acerca da simbiótica relação entre desenvolvimento tecnológico e desenvolvimento social na formação e atuação dos profissionais de Engenharia. Através de uma abordagem qualitativa, por meio de entrevistas semiestruturadas com 29 (vinte e nove) professores de 5 (cinco) cursos de Engenharia da Universidade Federal da Fronteira Sul (UFFS), as análises e categorizações foram realizadas usando a metodologia de Análise de Conteúdo. A prevalência de concepções tradicionais acerca do desenvolvimento tecnológico reforça a falta de entendimento e comprometimento acerca do papel social da Engenharia e revela a dificuldade de superação de modelos formativos historicamente consolidados.

No décimo artigo, o íon sódio é usado como temática científica na apresentação de uma proposta de ensino-aprendizagem de Química utilizando-se da metodologia experimental. Os pesquisadores utilizaram a técnica volumétrica de precipitação, nas especificidades do método de Mohr, propondo a análise do teor do íon sódio em um alimento ultraprocessado a partir de uma situação-problema potencialmente articulável à distintos níveis de ensino. $O$ estudo buscou incentivar/qualificar novas atribuições didático-experimentais dos temas da Química.

Ainda na área do Ensino de Química, o próximo artigo buscou analisar a complexidade com que esta área tem sido relatada na literatura, requerendo de professores novas práticas pedagógicas, sendo a experimentação muito discutida como uma alternativa viável neste processo. Através de uma pesquisa bibliográfica de caráter exploratório, os autores analisaram artigos publicados no período de 2008 -2019 nas revistas Química Nova na Escola e Revista Electrônica de Enseñanza de las Ciências, resultando em 10 trabalhos que abordavam a Resolução de Problemas aliada a Experimentação. Neste sentido, os autores concluíram que a integração dessas metodologias ainda é pouco explorada no contexto do Ensino de Química.

O próximo artigo trata sobre o livro didático, principal instrumento utilizado por professores no planejamento e desenvolvimento de sua prática pedagógica, que comumente se utiliza de 'analogias' como estratégia no tratamento de conceitos de difícil entendimento. 0 artigo mostra os resultados de um estudo crítico acerca dos aspectos organizacionais do volume 3 da coleção 'Ser protagonista - Química', adotado no Ensino Médio, destacando uma apreciação sobre as analogias nele presentes. Os autores observaram uma baixa frequência de analogias no livro. $O$ estudo revelou ainda a importância e eficácia da análise reflexiva durante o processo de escolha dos manuais didáticos e também dos raciocínios analógicos.

No décimo terceiro artigo, são apresentadas discussões resultados de pesquisas e estudos realizados no grupo de pesquisa Difusão do Conhecimento, Educação, Tecnologias e Modelagens Sociais (DCETM), da Universidade Estadual da Bahia (UNEB). $\mathrm{O}$ artigo abordando o desdobramento empírico de uma prática docente desenvolvida a partir da utilização de um sistema de gerenciamento de conteúdos para ambientes escolares. Para a coleta de dados, foi aplicado um questionário digital para nove turmas de primeiro semestre. Da analise dos resultados, os autores identificaram que o uso desse sistema pode potencializar o processo de ensino e aprendizagem.

Na sequência temos um artigo que analisa as possibilidades de transpor para as salas de aula de Ciências e Matemática da Educação Básica a adaptação do modelo atencional de Posner. 
Os autores concluem que apesar das principais pesquisas sobre atenção não tenham sido conduzidas para a resolução de problemas específicos da educação, alguns aspectos têm sido tratados na tentativa de entender o que se passa na cabeça do aluno enquanto ele tenta aprender, resultando, portanto, num modelo de atenção com base no modelo de Posner.

Dando continuidade, o próximo artigo, buscou analisar jogos que foram desenvolvidos por uma bolsista do PIBID e durante os Estágios supervisionados de um curso de Licenciatura em Química. Ao todo são apresentados e analisados 8 jogos, todos classificados como sendo de competição, caracterizados como jogos de cartas ou de tabuleiro. Todos os jogos apresentaram o nível de interação II por terem como característica sua utilização em sala de aula na revisão de conteúdos de determinada área de conhecimento.

No décimo sexto artigo desta edição, os autores buscaram mapear os kits de Robótica utilizados para o ensino de matemática e quais os conteúdos matemáticos trabalhados, através de uma Revisão Sistemática de Literatura, de pesquisas desenvolvidas no Brasil, nos últimos 10 anos. Os resultados apontaram que os resultados para o ensino de Matemática foram satisfatórios, pois propiciaram experiências concretas entre teoria e prática. Os autores destacam o potencial de trabalhar a Robótica com outras áreas de conhecimento, de forma interdisciplinar ou transdisciplinar.

O próximo artigo, analisou as publicações no Encontro Nacional de Pesquisa em Educação em Ciências (ENPEC) sobre abordagem CTS (Ciência, Tecnologia e Sociedade) no Ensino de Química. Os 46 artigos selecionados foram analisados a partir dos pressupostos da análise de conteúdo de Bardin. Os trabalhos são na maioria de natureza empírica, envolvendo uma diversidade de temas socioambientais. A análise indicou Wildson L. P. Santos como o principal referencial teórico citado. A pesquisa mostrou que, apesar de uma pequena tendência de aumento de publicações CTS no Ensino de Química nas edições do ENPEC, faz-se necessária reflexão sobre a inserção da abordagem CTS em sala de aula com foco na interdisciplinaridade.

O último artigo desta edição, faz uma análise de como o conteúdo de reprodução humana é ministrado, avaliando o uso de diferentes recursos didáticos. A pesquisa foi realizada com professores de escolas públicas e particulares e seis diferentes recursos didáticos no ensino de reprodução humana com duas turmas do 8 o ano do ensino fundamental de uma Escola Estadual no município de São Mateus-ES. Para coleta de dados foram aplicados questionários semiestruturados para os professores e alunos, ficando evidente que os recursos didáticos ajudaram no processo de ensino/aprendizagem, apesar das dificuldades apontadas pelos professores.

Fechando está edição, temos um Relato de Experiência que apresenta resultados de uma dissertação de mestrado sobre o uso do software LibreOffice Draw, como estratégia pedagógica, para o ensino de mapa de riscos ambientais. A prática foi desenvolvida em um curso técnico de Segurança do Trabalho, no interior do estado do Pará, com a participação de 20 alunos e 2 professores. Os materiais de coleta de dados foram os mapas setoriais e gerais confeccionados pelos alunos, entrevistas, filmagens, fotografias, gravações das aulas e um questionário de opinião. Trata-se de uma pesquisa qualitativa, com procedimentos técnicos de pesquisaparticipante, onde a docência aconteceu de forma mediadora e os discentes foram orientados a buscar autonomia e colaboração nas aprendizagens.

Assim, mais esta edição da ENCITEC é disponibilizada e desejo a todos uma boa leitura. 